\title{
Down-Expression of miRNA-98 and Over-Expression of miRNA-9 Can Result in Inadequate Immune System Response against Lung Cancer
}

\author{
Behrooz Farzanegan 1(D), Naghmeh Bahrami ${ }^{2}$ (D), Behnaz Birjandi ${ }^{3}$ (D), Adnan Khosravi ${ }^{(1 D}$, Abdollah \\ Farhadi Nasab 5,*iD, Mohammad Fathi ${ }^{3}{ }^{(D)}$, Mehdi Kazem Pour Dizaj ${ }^{6}{ }^{\mathbb{D}}$, Mahya Daustani ${ }^{7}$ (D) Elham \\ Askari $^{8}$ (D), Abdolreza Mohamadnia ${ }^{8,9, *(D)}$, Ali Akbar Velayati 10 (D)
}

1 Critical Care Quality Improvement Research Center at Shahid Modarres Hospital, Department of Anaesthesiology, Shahid Beheshti University of Medical Sciences, Tehran, Iran.Tracheal Diseases research center, National Research Institute of Tuberculosis and Lung Diseases (NRITID), Shahid Beheshti University of Medical Sciences, Tehran, Iran; farzaneganbehrooz@gmail.com (B.F.);

2 Department of Tissue Engineering and Applied Cell Sciences, School of Advanced Technologies in Medicine, Tehran University of Medical Sciences, Tehran, Iran Craniomaxillofacial Research Center, Tehran University of Medical Sciences, Tehran, Iran; naghmehbahrami@gmail.com (N.B.);

3 Anesthesiology Research Center, Anesthesia and Critical Care Department, Shahid Modares Hospital, Shahid Beheshti University of Medical Sciences, Tehran, Iran; behnaz.birjandi@gmail.com (B.B.), Fathi_mansor@yahoo.com (M.F.);

4 Tobacco Prevention and Control Research Center, National Research Institute of Tuberculosis and Lung Diseases (NRITLD), Shahid Beheshti University of Medical Sciences, Tehran, Iran; adkhosravi@ yahoo.com (A.K.);

5 Behavioral Sciences Research Center, Shahid Beheshti University of Medical Sciences, Tehran, Iran; farhadinasab@yahoo.com (A.F.N.);

6 Biostatistics Department, Mycobacteriology Research Center, National Research Institute of Tuberculosis and Lung Diseases, Masih Daneshvari Hospital, Shahid Beheshti University of Medical Sciences, Tehran, Iran; kazempoor@hotmail.com (M.K.P.D.);

7 Department of Biotechnology, Faculty of Sciences, Islamic Azad University, Tehran, Iran; mahya.daustany@gmail.com (M.D.);

8 Chronic Respiratory Diseases Research Center, National Research Institute of Tuberculosis and Lung Diseases (NRITLD), Shahid Beheshti University of Medical Sciences, Tehran, Iran; dr_elham_askari@yahoo.com (E.A.);

9 Department of Biotechnology, School of Advanced Technologies in Medicine, Shahid Beheshti University of Medical Sciences, Tehran, Iran; Mohamadnia.ar@gmail.com (A.M.);

10 Mycobacteriology Research Centre (MRC), National Research Institute of Tuberculosis and Lung Disease (NRITLD), Shahid Beheshti University of Medical Sciences, Tehran, Iran; aavelayati@ sbmu.ac.ir (A.A.V.);

* Correspondence: mohamadnia.ar@gmail.com (A.M.); farhadinasab@yahoo.com (A.F.N.);

Scopus Author ID 25959555400 (A.F.N.)

Received: 26.01.2021; Revised: 20.02.2021; Accepted: 23.02.2021; Published: 1.03.2021

Abstract: Lung cancer is a disease presenting high incidence and mortality rates. Its most common type is non-small cell lung cancer (NSCLC), constituting about $80-85 \%$ of all cases. MicroRNAs (miRNAs) are the molecules playing a role in the regulation of genes. Two crucial cytokines in cancer are interleukin (IL)-10 and IFN- $\gamma$. Our objective was to investigate the expression of miRNA-9, miRNA98, JAK, and STAT3 in patients with NSCLC and detect the cytokine level of IL-10. A total of 50 patients with NSCLC participated in this study. Besides, 50 healthy blood samples were selected as the control group. Real-time PCR determined the expression levels of miRNAs so that the RNAs extracted from the patients' peripheral mononuclear cells (PBMC) were initially synthesized, and cDNA was then extracted. Finally, the synthesized cDNA was amplified using real-time PCR, and its expression was compared to the control group. ELISA technique was used to detect IL-10 in plasma. Our result showed a low level of expression of miRNA-98, JAK, and STAT3 and a high-level expression of miRNA-9. ELISA test indicated a high cytokine level of IL-10 in the NSCLC patients' serum compared to the healthy controls. MiRNA-9 could suppress JAK and STAT3 genes in the NSCLC patients, which causes 
the poor immune response against the cell's proliferation. Besides, IL-10 was enhanced when miRNA98 was reduced. Therefore, the elevation of IL-10, as an anti-inflammatory cytokine, could lead to lung cancer progression without a strong immune system response.

Keywords: NSCLC; miRNA-9; miRNA-98; JAK, STAT3; real-time PCR.

(C) 2021 by the authors. This article is an open-access article distributed under the terms and conditions of the Creative Commons Attribution (CC BY) license (https://creativecommons.org/licenses/by/4.0/).

\section{Introduction}

Lung cancer is the leading cancer killer in both males and females worldwide. After breast and digestive cancers, this cancer type accounts for the most prevalent cancer among men and the third most frequent cancer among women [1-3]. Histologically, there are two major types of lung cancer: non-small (NSCLC) and small (SCLC) cell lung cancer, causing the annual mortality of about 1.2 million people worldwide. Evidence has shown the inflammatory process as one of the potential factors of cancer. Tuberculosis (TB), pneumonia, and chronic bronchitis are among the most leading inflammation-inducing factors in the lungs; however, TB has a more profound role in cancer emergence [4-6].

IFN- $\gamma$ is the key player in anti-tumor responses and induces the expression of PD-L1, a well-established inhibitor of anti-tumor immune function. Understanding the molecular signaling mechanism by which IFN- $\gamma$ regulates might improve its anti-tumor efficacy [7-9]. Although several cytokines and hormones can modulate cell proliferation activity, the predominant activator of some cytokines, such as IFN- $\gamma$ and interleukin (IL)-10, has an essential role in the immune system. The signal transduction pathway initiated by IFN- $\gamma$ is increasingly well characterized. The binding of IFN- $\gamma$ to cell surface receptors results in the activation of the tyrosine kinases JAK13 and JAK2, leading to the phosphorylation of cytoplasmic STAT1, which its phosphorylation on Tyr701 gives rise to the dimerization and nuclear translocation. Janus kinases (JAKs) and signal transducers and activators of transcription (STATs) are the central proteins of the JAK-STAT signaling pathway, and when activated, it is known to stimulate cell proliferation, differentiation, cell migration, and apoptosis [10,11]. IL-10 is required for T-helper cell functions, T-cell immune surveillance, and suppression of cancer-associated inflammation. By promoting tumor-specific immune surveillance and hindering pathogenic inflammation, IL-10 could emerge as a key cytokine in the battle of the host against cancer [12].

MicroRNAs (miRNAs) are single-stranded RNA molecules and can influence cell proliferation and differentiation. These molecules have the ability to bind to the 3'-UTR of cognate mRNAs, thereby giving rise to the degradation of mRNA. They are also responsible for numerous diseases, such as lung inflammatory disorders [13-16]. MiRNA-98 negatively regulates IL-10 production and endotoxin tolerance in macrophages after lipopolysaccharide stimulation [17] and interferes with the expression of IL-10 in peripheral B cells of patients with lung cancer [18]. miRNA-9 is a highly conserved miRNA found in insects and primates [19]. Ectopic expression of miRNA-9 in HeLa has been demonstrated to inhibit JAK/STAT3 signaling activity. The tumor suppressor potential of miRNA-9 could also repress tumorigenesis by inhibiting IL-6/JAK/STAT3 pathway [20].

There are various molecular tests for a lung cancer diagnosis; however, the commonly used test systems are still insufficient. Owing to the limited knowledge of lung cancer biomarkers, we designed this study in the hope of finding miRNAs as biomarkers for the 
diagnosis of lung cancer and identifying all the molecules that have a crucial role in lung cancer progression.

\section{Materials and Methods}

\subsection{Sampling.}

Peripheral mononuclear cells (PBMC) were obtained from healthy donors. This study conformed to the principles outlined in the Declaration of Helsinki for human blood use and was approved by the Ethics Committee of Experimental Research, Shahid Beheshti University of Medical Sciences, Tehran, Iran.( IR.SBMU.RETECH.REC.1398.107) At first, $5 \mathrm{ml}$ of venous blood was acquired from each individual and kept in a refrigerator. Peripheral venous blood ( $1 \mathrm{ml})$ was then collected from patients and controls by standard venipuncture using EDTA-containing tubes after clotting. The specimens were finally centrifuged at $5000 \mathrm{rpm}$ at room temperature for $15 \mathrm{~min}$ to separate the serum.

\subsection{Total RNA extraction, cDNA generation, and real-time PCR.}

RNA was obtained from whole blood samples. According to the manufacturer's instruction, the total RNA was purified with Trizol reagent using miRcute miRNA Isolation Kit (Invitrogen, Life Technologies, USA). The reagent was then put into the kit and shook well. The solution was transferred to $1.5-\mathrm{ml}$ tubes using chloroform and centrifuged at 12,000 rpm at $4^{\circ} \mathrm{C}$ for $15 \mathrm{~min}$. After placing in pressure equalizer tubes containing isopropanol, the supernatant was centrifuged at $12,000 \mathrm{rpm}$ at $4{ }^{\circ} \mathrm{C}$ for $15 \mathrm{~min}$, and the precipitate was kept. The precipitate was treated with ethanol, and diethylpyrocarbonate was used to dissolve the precipitate. The NanoDrop 1000 spectrophotometer (NanoDrop Technologies, Wilmington, Delaware, USA) was employed to determine RNA concentration by using agarose gel electrophoresis. The size fractionation of DNA fragments was evaluated by gel electrophoresis on a $1 \%$ agarose gel. To generate cDNA from miRNA, we applied a hairpin primer and an RNA-dependent reverse transcriptase with the aid of a Master Mix Kit (Takara, Japan) on a Rotor-Gene (Qiagen, Germany). All the RNA samples were treated with DNase I enzyme to avoid DNA contamination. Real-time PCR was performed in triplicates using a Roche Realtime (LightCycler 480, Germany) system. Glyceraldehyde 3-phosphate dehydrogenase (GAPDH) was used as an endogenous control for conventional genes (STAT3 and JAK). The primer sequences of STAT3, JAK, and GAPDH are illustrated in Table 1.

Table 1. Sequences used to detect the expression levels of genes in real-time PCR.

\begin{tabular}{l|l|l} 
Genes & & Sequences \\
\hline$J A K$ & $\mathrm{~F}$ & GACCGTCACCTGCTTTGAGA \\
& $\mathrm{R}$ & TGATATTCTCCACGTCGCGG \\
\hline STAT3 & $\mathrm{F}$ & ATTCTGGCTTCCTTCCTGCC \\
& $\mathrm{R}$ & GCTGAGGCAAGGTGGTTTG \\
\hline GAPDH & $\mathrm{F}$ & 5`AATCCCATCACCATCTTCCA-3` \\
& $\mathrm{R}$ & 5-AAATGAGCCCCAGCCTTC-3
\end{tabular}

\subsection{IL-10 measurement.}

The secreted IL-10 was evaluated with ELISA (IL-10 assay, eBiosciences, USA). The results were expressed as pictograms per milliliter. 


\subsection{Statistical analysis.}

All the data were analyzed using Graph Pad Prism version 2. Differences between the groups were examined for statistical significance with an unpaired student $t$-test. A $p$-value less than 0.05 was considered statistically significant.

\section{Results and Discussion}

\subsection{Analysis of miRNAs levels expression in PBMC.}

MiRNA-9, JAK, STAT3, and miRNA-98 gene expression and the serum levels of IL10 secretion were compared in NSCLC patients with the healthy controls. The results revealed the miRNA-9 expression level of $3.22 \pm 0.23$ in the patients and $1.16 \pm 0.17$ in the healthy controls, representing a notably significant increase $(p=0.022$; Figure 1$)$.

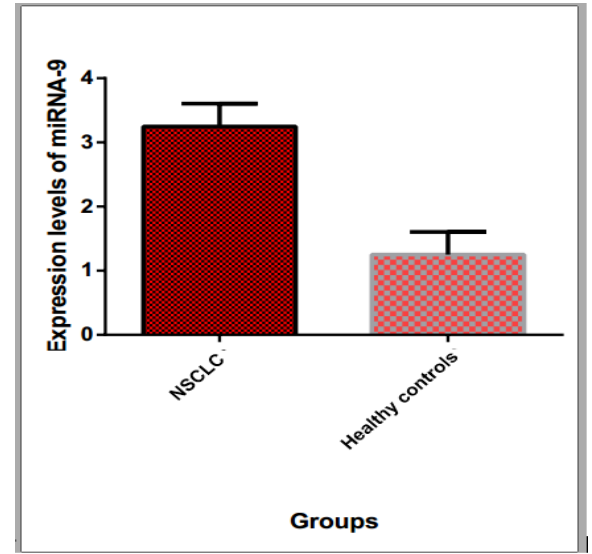

Figure 1. The expression levels of miRNA-9 significantly increased in non-small cell lung cancer (NSCLC) patients.

This study's key point is that the mRNA levels of JAK and STAT3 significantly decreased in both groups (Figures 2 and 3). After analyzing the data, we found that the expression level of JAK in the patients was $0.53 \pm 0.02$, while in the healthy group, it was $1.1 \pm 0.02(p=0.026)$. Like the expression level of JAK, STAT3 indicated a reduction in its expression level in the patients $(0.33 \pm 0.01)$ compared to the healthy controls $(1.2 \pm 0.03)$.

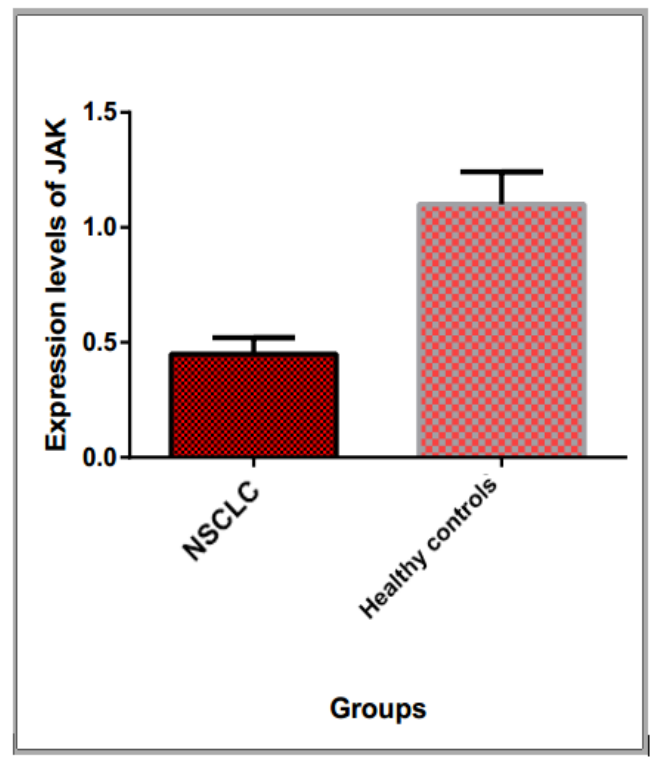

Figure 2. The expression levels of JAK significantly decreased in non-small cell lung cancer (NSCLC) patients. 


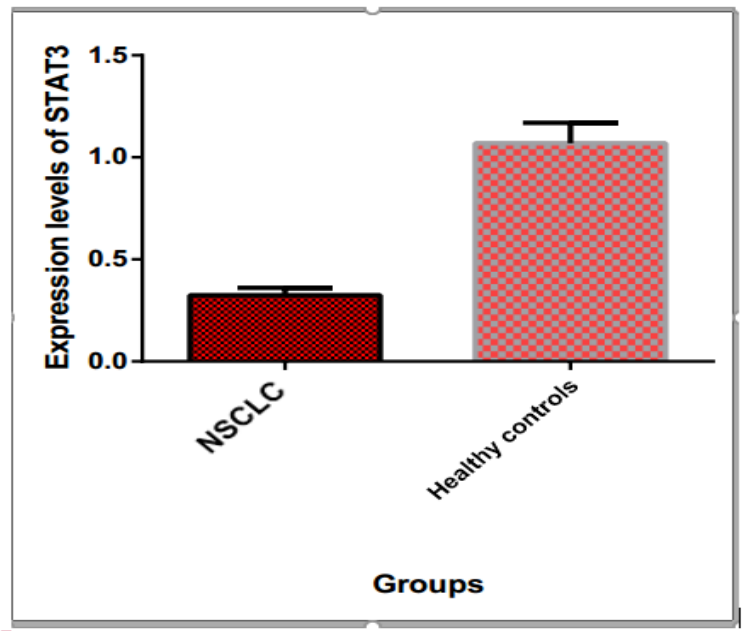

Figure 3. The expression levels of STAT3 significantly decreased in non-small cell lung cancer (NSCLC) patients.

The miRNA-98 expression level, which was $0.24 \pm 0.01$ in the patients and $1.1 \pm 0.02$ in the healthy controls $(p=0.031)$, dramatically decreased in NSCLC patients (Figure 4).

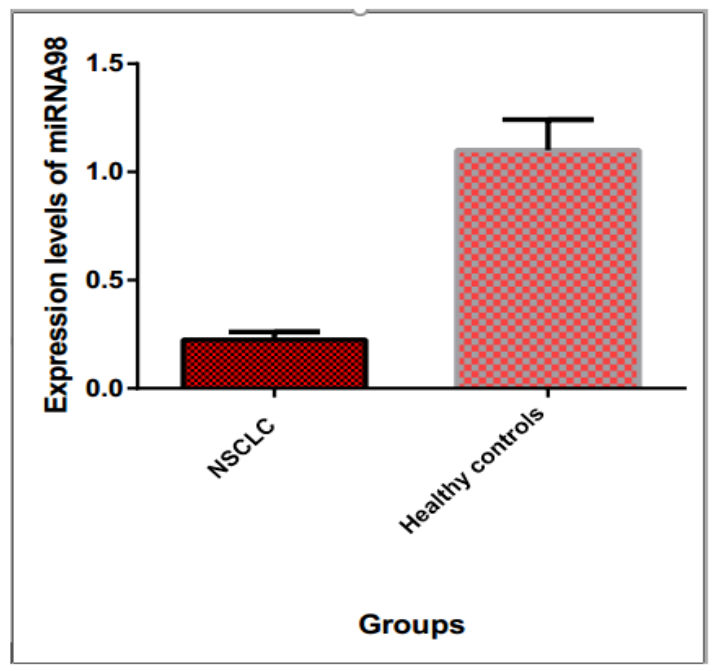

Figure 4. The expression levels of miRNA-98 significantly decreased in non-small cell lung cancer (NSCLC) patients.

The serum levels of IL-10 showed a significant increase in the patients $(7.2 \pm 0.3)$ in comparison to the healthy controls $(4.16 \pm 0.31 ; p=0.001$; Figure 5$)$.

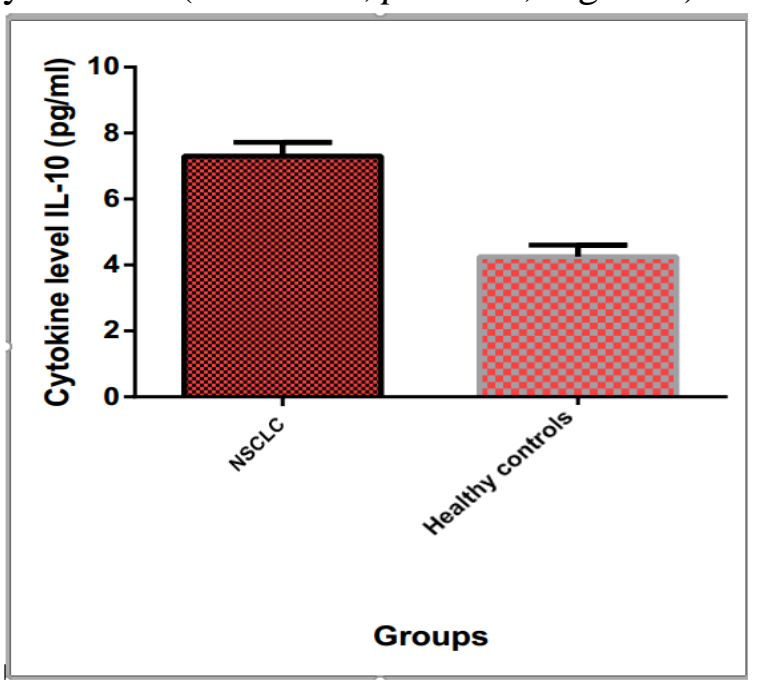

Figure 5. The serum level of IL-10 significantly increased in non-small cell lung cancer (NSCLC) patients. 
Studies have addressed miRNAs' differential expression as reflecting disease prediction and progression in vivo and in vitro [21-24]. Here, we discuss miRNA-9 and miRNA-98 in lung cancer patients, as well as evaluate the expression levels of JAK, STAT3, and IL-10. Although the role of miRNA-9 in carcinogenesis has been reviewed in several kinds of human malignancies, the biological function of this miRNA type in cancer is still not well understood, and its role in lung cancer remains unclear.

Our result suggested that miRNA-9 enhanced in the lung cancer patients in comparison to the healthy controls. The function of miRNA-9 varies with different tumor contexts and varied cancer development stages. In certain human cancers, e.g., breast, colon, and gastric cancers, miRNA-9 was detected to be silent by hypermethylation and recognized as a tumor suppressor by targeting oncogenes, e.g., NF (nuclear factor)-kappaB1, CDX2, and MTHFD2 [25-31]. Moreover, miRNA-9 induces overexpression in metastasizing tumor tissues of breast and liver cancers compared to primary cancer tissues [32-34]. In the human genome, there are three independent miRNA-9 precursors, miRNA-9-1, miRNA-9-2, and miRNA-9-3, encoding the same mature miRNA-9. Dysregulation of miRNA-9 expression deeply affects cancer development; nonetheless, it seems that miRNA-9 has inverse functions in various tissues or under multiple cancer contexts by targeting different genes. In brain tumors, miRNA-9 is overexpressed [35,36]. In breast and colorectal cancers, it induces cell metastasis by enhancing cell motility by targeting E-cadherin [32,37], which denotes the oncogenic potential of miRNA-9. In contrast, in gastric and ovarian cancers and malignant melanoma, miRNA-9 has the ability to inhibit cell growth and metastasis via targeting NF-kappaB1 [25,38,39], signifying the tumor-suppressor role of miRNA-9. Even in the same type of cancer, e.g., breast cancer, miRNA-9 could exert anti-proliferating and pro-metastasizing functions through targeting MTHFD2 and E-cadherin, respectively [32,40]. Accordingly, the function of miRNA-9 is greatly dependent on its downstream target genes.

IL-10 is an acid-sensitive homodimeric and a major immunosuppressive, pro-tumoral cytokine. This pleiotropic molecule possesses an anti-inflammatory function, which regulates autoimmunity, cell proliferation, survival, apoptosis, and angiogenesis. IL-10 is chiefly secreted by M2 macrophages, Tregs, and Th2 cells, but bronchial epithelial cells, the initial source of NSCLC, can also release IL-10 [41-44].

Tumor-associated macrophages are generally recognized as a promoter of tumor progression. miRNA-98 has been shown to suppress the proliferation, migration, invasion, and epithelial-mesenchymal transition of HCC cells $[45,46]$. However, its role in the pathogenesis of lung cancer is not yet fully understood. Earlier investigations have evidenced that miRNA98 could serve as a therapeutic target for the inhibition of prostate cancer growth and also as a biomarker induced by vitamin D [47,48]. It has also been demonstrated that miRNA-98 could prevent the migration and invasion of human esophageal squamous cell carcinoma by regulating the enhancer of zeste homolog 2 (EZH2) [49,50]. EZH2-specific miRNA-98 has suggested inhibiting the proliferation of human ovarian cancer stem cell-like cells by regulating the pRb-E2F pathway [51], and miRNA-98 may not directly, but through the intermediate factor, takes part in the pathogenesis of human cancer. In the present study, miRNA-98 inhibited cell proliferation, migration, and invasion in lung cancer cells and negatively regulated ITGB3 expression via binding miRNA-98 to the 3'-UTR of ITGB3 mRNA [52]. 


\section{Conclusions}

We found that miRNA-9 can inhibit JAK and STAT3, as protein adaptors, in the cell signaling and can result in immune response deficiency, pushing cells to proliferation in lung cancer patients. In addition, miRNA-98 decreased in the patients, while IL-10 increased. Since IL-10 is an anti-inflammatory cytokine, its elevation can result in lung cancer progression without a strong immune system response.

\section{Funding}

This research received no external funding.

\section{Acknowledgments}

This research has no acknowledgments.

\section{Conflicts of Interest}

The authors declare no conflict of interest.

\section{References}

1. Liang, H.Y.; Li, X.L.; Yu, X.S.; Guan, P.; Yin, Z.H.; He, Q.C.; Zhou, B.S. Facts and fiction of the relationship between preexisting tuberculosis and lung cancer risk: a systematic review. Int. J. Cancer 2009, 125, 29362944, https://doi.org/10.1002/ijc.24636.

2. National Lung Screening Trial Research, T. Reduced lung-cancer mortality with low-dose computed tomographic screening. New Engl. J. Med. 2011, 365, 395-409.

3. Bodor, J.N.; Boumber, Y.; Borghaei, H. Biomarkers for immune checkpoint inhibition in non-small cell lung cancer (NSCLC). Cancer 2020, 126, 260-270, https://doi.org/10.1002/cncr.32468.

4. Brenner, D.R.; McLaughlin, J.R.; Hung, R.J. Previous lung diseases and lung cancer risk: a systematic review and meta-analysis. PLoS One 2011, 6, e17479, https://doi.org/10.1371/journal.pone.0017479.

5. Maharjan, N.; Thapa, N.; Tu, J. Blood-Based biomarkers for early diagnosis of lung cancer: A review article. JNMA J. Nepal Med. Assoc. 2020, 58, 519.

6. Niu, Y.; Su, M.; Wu, Y.; Fu, L.; Kang, K.; Li, Q.; Li, L.; Hui, G.; Li, F.; Gou, D. Circulating Plasma miRNAs as Potential Biomarkers of Non-Small Cell Lung Cancer Obtained by High-Throughput Real-Time PCR Profiling. Cancer Epidemiol. Biomarkers Prev. 2019, 28, 327-336, https://doi.org/10.1158/1055-9965.Epi18-0723.

7. Shankaran, V.; Ikeda, H.; Bruce, A.T.; White, J.M.; Swanson, P.E.; Old, L.J.; Schreiber, R.D. IFNgamma and lymphocytes prevent primary tumour development and shape tumour immunogenicity. Nature 2001, 410, 1107-1111, https://doi.org/10.1038/35074122.

8. Rossi, G.; Russo, A.; Tagliamento, M.; Tuzi, A.; Nigro, O.; Vallome, G.; Sini, C.; Grassi, M.; Dal Bello, M.G.; Coco, S.; Longo, L.; Zullo, L.; Tanda, E.T.; Dellepiane, C.; Pronzato, P.; Genova, C. Precision Medicine for NSCLC in the Era of Immunotherapy: New Biomarkers to Select the Most Suitable Treatment or the Most Suitable Patient. Cancers (Basel) 2020, 12, https://doi.org/10.3390/cancers12051125.

9. Chen, S.; Crabill, G.A.; Pritchard, T.S.; McMiller, T.L.; Wei, P.; Pardoll, D.M.; Pan, F.; Topalian, S.L. Mechanisms regulating PD-L1 expression on tumor and immune cells. Journal for ImmunoTherapy of Cancer 2019, 7, 305, https://doi.org/10.1186/s40425-019-0770-2.

10. de Weerd, N.A.; Nguyen, T. The interferons and their receptors-distribution and regulation. Immunol. Cell Biol. 2012, 90, 483-491, https://doi.org/10.1038/icb.2012.9.

11. Kang, D.Y.; Sp, N.; Jo, E.S.; Rugamba, A.; Hong, D.Y.; Lee, H.G.; Yoo, J.-S.; Liu, Q.; Jang, K.-J.; Yang, Y.M. The Inhibitory Mechanisms of Tumor PD-L1 Expression by Natural Bioactive Gallic Acid in NonSmall-Cell Lung Cancer (NSCLC) Cells. Cancers (Basel) 2020, 12, 727, https://doi.org/10.3390/cancers12030727. 
12. Moore, K.W.; O'Garra, A.; Malefyt, R.d.; Vieira, P.; Mosmann, T.R. Interleukin-10. Annu. Rev. Immunol. 1993, 11, 165-190.

13. Wilusz, J.E.; Sunwoo, H.; Spector, D.L. Long noncoding RNAs: functional surprises from the RNA world. Genes Dev. 2009, 23, 1494-1504, https://doi.org/10.1101/gad.1800909.

14. Wu, K.-L.; Tsai, Y.-M.; Lien, C.-T.; Kuo, P.-L.; Hung; Jen, Y. The Roles of MicroRNA in Lung Cancer. Int. J. Mol. Sci. 2019, 20, 1611, https://doi.org/10.3390/ijms20071611.

15. Naeli, P.; Yousefi, F.; Ghasemi, Y.; Savardashtaki, A.; Mirzaei, H. The Role of MicroRNAs in Lung Cancer: Implications for Diagnosis and Therapy. Curr. Mol. Med. 2020, 20, 90-101, https://doi.org/10.2174/1566524019666191001113511.

16. Iqbal, M.A.; Arora, S.; Prakasam, G.; Calin, G.A.; Syed, M.A. MicroRNA in lung cancer: role, mechanisms, pathways and therapeutic relevance. Mol. Aspects Med. 2019, 70, 3-20, https://doi.org/10.1016/j.mam.2018.07.003.

17. Liu, Y.; Chen, Q.; Song, Y.; Lai, L.; Wang, J.; Yu, H.; Cao, X.; Wang, Q. MicroRNA-98 negatively regulates IL-10 production and endotoxin tolerance in macrophages after LPS stimulation. FEBS Lett. 2011, 585, 19631968, https://doi.org/10.1016/j.febslet.2011.05.029.

18. Li, Y.; Rong, J.; Qin, J.; He, J.-y.; Chen, H.-g.; Huang, S.-h. Micro RNA-98 interferes with expression interleukin-10 in peripheral B cells of patients with lung cancer. Sci. Rep. 2016, 6, 32754, https://doi.org/10.1038/srep32754.

19. Li, S.C.; Chan, W.C.; Hu, L.Y.; Lai, C.H.; Hsu, C.N.; Lin, W.C. Identification of homologous microRNAs in 56 animal genomes. Genomics 2010, 96, 1-9, https://doi.org/10.1016/j.ygeno.2010.03.009.

20. Zhang, J.; Jia, J.; Zhao, L.; Li, X.; Xie, Q.; Chen, X.; Wang, J.; Lu, F. Down-regulation of microRNA-9 leads to activation of IL-6/Jak/STAT3 pathway through directly targeting IL-6 in HeLa cell. Mol. Carcinog. 2016, 55, 732-742, https://doi.org/10.1002/mc.22317.

21. Meiri, E.; Mueller, W.C.; Rosenwald, S.; Zepeniuk, M.; Klinke, E.; Edmonston, T.B.; Werner, M.; Lass, U.; Barshack, I.; Feinmesser, M.; Huszar, M.; Fogt, F.; Ashkenazi, K.; Sanden, M.; Goren, E.; Dromi, N.; Zion, O.; Burnstein, I.; Chajut, A.; Spector, Y.; Aharonov, R. A second-generation microRNA-based assay for diagnosing tumor tissue origin. Oncologist 2012, 17, 801-812, https://doi.org/10.1634/theoncologist.20110466.

22. van de Worp, W.R.P.H.; Schols, A.M.W.J.; Dingemans, A.-M.C.; Op den Kamp, C.M.H.; Degens, J.H.R.J.; Kelders, M.C.J.M.; Coort, S.; Woodruff, H.C.; Kratassiouk, G.; Harel-Bellan, A.; Theys, J.; van Helvoort, A.; Langen, R.C.J. Identification of microRNAs in skeletal muscle associated with lung cancer cachexia. Journal of Cachexia, Sarcopenia and Muscle 2020, 11, 452-463, https://doi.org/10.1002/jcsm.12512.

23. Syed, M.H.; Zamzam, A.; Valencia, J.; Khan, H.; Jain, S.; Singh, K.K.; Abdin, R.; Qadura, M. MicroRNA Profile of Patients with Chronic Limb-Threatening Ischemia. Diagnostics (Basel, Switzerland) 2020, 10, https://doi.org/10.3390/diagnostics10040230.

24. Hu, C.; Meiners, S.; Lukas, C.; Stathopoulos, G.T.; Chen, J. Role of exosomal microRNAs in lung cancer biology and clinical applications. Cell Prolif. 2020, 53, e12828, https://doi.org/10.1111/cpr.12828.

25. Wan, H.-Y.; Guo, L.-M.; Liu, T.; Liu, M.; Li, X.; Tang, H. Regulation of the transcription factor NF- $\kappa$ B1 by microRNA-9 in human gastric adenocarcinoma. Mol. Cancer 2010, 9, 16, https://doi.org/10.1186/1476-45989-16.

26. Lehmann, U.; Hasemeier, B.; Christgen, M.; Müller, M.; Römermann, D.; Länger, F.; Kreipe, H. Epigenetic inactivation of microRNA gene hsa-mir-9-1 in human breast cancer. J. Pathol. 2008, 214, 17-24, https://doi.org/10.1002/path.2251.

27. Bandres, E.; Agirre, X.; Bitarte, N.; Ramirez, N.; Zarate, R.; Roman-Gomez, J.; Prosper, F.; Garcia-Foncillas, J. Epigenetic regulation of microRNA expression in colorectal cancer. Int. J. Cancer 2009, 125, 2737-2743, https://doi.org/10.1002/ijc.24638.

28. Hildebrandt, M.A.T.; Gu, J.; Lin, J.; Ye, Y.; Tan, W.; Tamboli, P.; Wood, C.G.; Wu, X. Hsa-miR-9 methylation status is associated with cancer development and metastatic recurrence in patients with clear cell renal cell carcinoma. Oncogene 2010, 29, 5724-5728, https://doi.org/10.1038/onc.2010.305.

29. Rotkrua, P.; Akiyama, Y.; Hashimoto, Y.; Otsubo, T.; Yuasa, Y. MiR-9 downregulates CDX2 expression in gastric cancer cells. Int. J. Cancer 2011, 129, 2611-2620, https://doi.org/10.1002/ijc.25923.

30. Tsai, K.-W.; Liao, Y.-L.; Wu, C.-W.; Hu, L.-Y.; Li, S.-C.; Chan, W.-C.; Ho, M.-R.; Lai, C.-H.; Kao, H.-W.; Fang, W.-L.; Huang, K.-H.; Lin, W.-c. Aberrant hypermethylation of miR-9 genes in gastric cancer. Epigenetics 2011, 6, 1189-1197, https://doi.org/10.4161/epi.6.10.16535. 
31. Tavakolian, S.; Goudarzi, H.; Torfi, F.; Faghihloo, E. Evaluation of microRNA-9 and -192 expression levels as biomarkers in patients suffering from breast cancer. Biomed Rep 2020, 12, 30-34, https://doi.org/10.3892/br.2019.1257.

32. Ma, L.; Young, J.; Prabhala, H.; Pan, E.; Mestdagh, P.; Muth, D.; Teruya-Feldstein, J.; Reinhardt, F.; Onder, T.T.; Valastyan, S.; Westermann, F.; Speleman, F.; Vandesompele, J.; Weinberg, R.A. miR-9, a MYC/MYCN-activated microRNA, regulates E-cadherin and cancer metastasis. Nat. Cell Biol. 2010, 12, 247-256, https://doi.org/10.1038/ncb2024.

33. Tan, H.X.; Wang, Q.; Chen, L.Z.; Huang, X.H.; Chen, J.S.; Fu, X.H.; Cao, L.Q.; Chen, X.L.; Li, W.; Zhang, L.J. MicroRNA-9 reduces cell invasion and E-cadherin secretion in SK-Hep-1 cell. Med. Oncol. 2010, 27, 654-660, https://doi.org/10.1007/s12032-009-9264-2.

34. Wu, J.; He, J.; Tian, X.; Li, H.; Wen, Y.; Shao, Q.; Cheng, C.; Wang, G.; Sun, X. Upregulation of miRNA9-5p Promotes Angiogenesis after Traumatic Brain Injury by Inhibiting Ptch-1. Neuroscience 2020, 440, 160174, https://doi.org/10.1016/j.neuroscience.2020.05.045.

35. Nass, D.; Rosenwald, S.; Meiri, E.; Gilad, S.; Tabibian-Keissar, H.; Schlosberg, A.; Kuker, H.; Sion-Vardy, N.; Tobar, A.; Kharenko, O.; Sitbon, E.; Lithwick Yanai, G.; Elyakim, E.; Cholakh, H.; Gibori, H.; Spector, Y.; Bentwich, Z.; Barshack, I.; Rosenfeld, N. MiR-92b and miR-9/9* are specifically expressed in brain primary tumors and can be used to differentiate primary from metastatic brain tumors. Brain pathology (Zurich, Switzerland) 2009, 19, 375-383, https://doi.org/10.1111/j.1750-3639.2008.00184.x.

36. Tan, X.; Wang, S.; Yang, B.; Zhu, L.; Yin, B.; Chao, T.; Zhao, J.; Yuan, J.; Qiang, B.; Peng, X. The CREBmiR-9 Negative Feedback Minicircuitry Coordinates the Migration and Proliferation of Glioma Cells. PLoS One 2012, 7, e49570, https://doi.org/10.1371/journal.pone.0049570.

37. Zhu, L.; Chen, H.; Zhou, D.; Li, D.; Bai, R.; Zheng, S.; Ge, W. MicroRNA-9 up-regulation is involved in colorectal cancer metastasis via promoting cell motility. Med. Oncol. 2012, 29, 1037-1043, https://doi.org/10.1007/s12032-011-9975-z.

38. Guo, L.M.; Pu, Y.; Han, Z.; Liu, T.; Li, Y.X.; Liu, M.; Li, X.; Tang, H. MicroRNA-9 inhibits ovarian cancer cell growth through regulation of NF-kappaB1. FEBS J. 2009, 276, 5537-5546, https://doi.org/10.1111/j.1742-4658.2009.07237.x.

39. Liu, S.; Kumar, S.M.; Lu, H.; Liu, A.; Yang, R.; Pushparajan, A.; Guo, W.; Xu, X. MicroRNA-9 up-regulates E-cadherin through inhibition of NF-KB1-Snail1 pathway in melanoma. J. Pathol. 2012, 226, 61-72, https://doi.org/10.1002/path.2964.

40. Selcuklu, S.D.; Donoghue, M.T.; Rehmet, K.; de Souza Gomes, M.; Fort, A.; Kovvuru, P.; Muniyappa, M.K.; Kerin, M.J.; Enright, A.J.; Spillane, C. MicroRNA-9 inhibition of cell proliferation and identification of novel miR-9 targets by transcriptome profiling in breast cancer cells. J. Biol. Chem. 2012, 287, 29516-29528, https://doi.org/10.1074/jbc.M111.335943.

41. Hatanaka, H.; Abe, Y.; Naruke, M.; Tokunaga, T.; Oshika, Y.; Kawakami, T.; Osada, H.; Nagata, J.; Kamochi, J.; Tsuchida, T.; Kijima, H.; Yamazaki, H.; Inoue, H.; Ueyama, Y.; Nakamura, M. Significant correlation between interleukin 10 expression and vascularization through angiopoietin/TIE2 networks in non-small cell lung cancer. Clin. Cancer. Res. 2001, 7, 1287-1292.

42. Teng, Michele W.L.; Darcy, Phillip K.; Smyth, Mark J. Stable IL-10: A New Therapeutic that Promotes Tumor Immunity. Cancer Cell 2011, 20, 691-693, https://doi.org/10.1016/j.ccr.2011.11.020.

43. Zheng, Z.; Huang, G.; Gao, T.; Huang, T.; Zou, M.; Zou, Y.; Duan, S. Epigenetic Changes Associated With Interleukin-10. Front. Immunol. 2020, 11, 1105.

44. Varghese, E.; Liskova, A.; Kubatka, P.; Samuel, S.M.; Büsselberg, D. Anti-Angiogenic Effects of Phytochemicals on miRNA Regulating Breast Cancer Progression. Biomolecules 2020, 10, https://doi.org/10.3390/biom10020191.

45. Li, L.; Sun, P.; Zhang, C.; Li, Z.; Cui, K.; Zhou, W. MiR-98 modulates macrophage polarization and suppresses the effects of tumor-associated macrophages on promoting invasion and epithelial-mesenchymal transition of hepatocellular carcinoma. Cancer Cell Int. 2018, 18, 95, https://doi.org/10.1186/s12935-0180590-3.

46. Wang, Y.; Zhang, J.; Su, Y.; Wang, C.; Zhang, G.; Liu, X.; Chen, Q.; Lv, M.; Chang, Y.; Peng, J. miRNA98-5p targeting IGF2BP1 Induces mesenchymal stem cell apoptosis by modulating PI3K/Akt and p53 in immune thrombocytopenia. Molecular Therapy-Nucleic Acids 2020, 20, 764-776.

47. Ting, H.J.; Messing, J.; Yasmin-Karim, S.; Lee, Y.F. Identification of microRNA-98 as a therapeutic target inhibiting prostate cancer growth and a biomarker induced by vitamin D. J. Biol. Chem. 2013, 288, 1-9, https://doi.org/10.1074/jbc.M112.395947. 
48. Qiu, K.; Xie, Q.; Jiang, S.; Lin, T. miR-98-5p promotes apoptosis and inhibits migration and cell growth in papillary thyroid carcinoma through Bax/Caspase-3 by HMGA2. J. Clin. Lab. Anal. 2020, 34, e23044, https://doi.org/10.1002/jcla.23044.

49. Huang, S.-D.; Yuan, Y.; Zhuang, C.-W.; Li, B.-L.; Gong, D.-J.; Wang, S.-G.; Zeng, Z.-Y.; Cheng, H.-Z. MicroRNA-98 and microRNA-214 post-transcriptionally regulate enhancer of zeste homolog 2 and inhibit migration and invasion in human esophageal squamous cell carcinoma. Mol. Cancer 2012, 11, 51, https://doi.org/10.1186/1476-4598-11-51.

50. Li, W.; Wang, J.; Zhang, D.; Zhang, X.; Xu, J.; Zhao, L. MicroRNA-98 targets HMGA2 to inhibit the development of retinoblastoma through mediating Wnt/ $\beta$-catenin pathway. Cancer Biomark. 2019, 25, 7988, https://doi.org/10.3233/CBM-182315.

51. Liu, T.; Hou, L.; Huang, Y. EZH2-specific microRNA-98 inhibits human ovarian cancer stem cell proliferation via regulating the pRb-E2F pathway. Tumour Biol. 2014, 35, 7239-7247, https://doi.org/10.1007/s13277-014-1950-9.

52. Ni, R.; Huang, Y.; Wang, J. miR-98 targets ITGB3 to inhibit proliferation, migration, and invasion of nonsmall-cell lung cancer. Onco Targets Ther. 2015, 8, 2689. 